\title{
Study on the structure of Chinese dual economy
}

\author{
Jing Huirong \\ School of Management, Yunnan University of Nationalities, Kunming, Yunnan, P.R.China \\ 1307608193@qq.com, goughuirong@aliyun.com
}

Keywords: dual economic structure, China's economic, urban and rural, economic structure

\begin{abstract}
This paper reviews the related theory to explain the present situation of China's urban and rural economic structure. Furthermore, the data of the urban and rural populations in China Statistical Yearbook is used to reveal the status of China's economic structure. It is found that the configuration proportion of capital and labor production factors in China's urban and rural economic structure is imbalance, The amounts of labor is much larger than the amounts of capital in the agricultural industry, the amounts of capital is greater than the amounts of labor input in non-agricultural industries, This directs the result of the inefficiency of the two sectors output.
\end{abstract}

\section{Introduction}

Rapid economic growth in China has aroused worldwide attention. The process of China's rapid economic growth is the process of China's dual economic structure changing. Revealing the law of Chinese dual economic structure changing will be in favor of the world's economic growth.

\section{The related theoretical explanation of the China's urban-rural dual economic structure}

The best theory to explain the present situation of China's urban and rural economic structure is a dual economic structure theory of Lewis and other researchers. The literature [1] built a theoretical model of dual economic structure, researched the economic development from the perspective of industrial and agricultural sector's labor demand and supply, and form its equilibrium.

In the literature [1]'s theory has been developed, The literature [2] noted that the role of agricultural surplus, and built the model based on literature [1] the Lewis dual economic model. Because born out of the model of literature [1], Descendants call it as the Lewis-Ranis-Fei model. Their main point is: the traditional sector of agriculture development relies on the output of surplus labor, the industrial sector acts as the power source of its own sustainable development and absorbing surplus labor, it promotes economic development which lies in the combination of surplus labor in agriculture and industrial capital. This is the original meaning of the dual economic structure.

The literature [3] Founded Jorgenson model based on the neo-classical economics perspective. He believed that the surplus agricultural labor is a necessary condition which transfer the labor from traditional sector to the modern sector, and agricultural surplus the greater, the faster development of the modern sector, the more smoothly transfer of the labor force in agriculture.

The research on China's economic structure has always been a hot issue of domestic theoretical discussion. These studies are basically based on the Lewis-Ranis-Fei model, there form a range of perspectives of China's economy dual structure, and derived ternary, quaternary economic structure theory.

The literature [4] believed that the current differences between the urban and rural dual economic structure is a growing trend. The literature [5] formed the focus from the perspective of Chinese agricultural, industrial markets, deconstructs the formation of China's dual economic structure. The literature [6] believed that China's production factor market duality showed independence and differences between urban and rural factor markets, such characteristics strengthen Chinese dual economic structure.

The literature [7] thought that China as the largest developing country had a typical urban-rural dual economic structure characteristics. And specifically pointed out that the characteristics of the 
China' dual economic structure was mainly concentrated in the following areas: industrial and agricultural development imbalanced; regional economic development disordered; urban-rural income gap was widening.

The literature [8] thought that: because China's specific national conditions, China's economic and social transformation experienced changing from the disintegration of the traditional agriculture to the urban-rural dual economic and social structures, to the establishment and improvement of the socialist market economic system and urban rapid development of four parts economic and social structures.

The literature [9] also believed that China's economy was characterized the dual economy structure which the rural was agriculture and the urban was industrial. He pointed out that: China's dual economic structure trended to strengthen the characteristics before the reform and opening up. The literature [10]pointed out that the Lewis model simple depicted the scene in the process of economic development in developing countries, it was an objective description of the early stages of development in developing countries, it was the classic model of analyzing the problem of dual economic structure.

In summary, the Lewis' dual economic structure theoretical model could explain the problem of China economic growth under the condition of funds shortage since China founding. However, all the studies existence do not from the production perspective give that the agricultural sector surplus labor combined with the industrial capital how to improve the economic outputs thereby contribute to economic growth..

\section{The status of China's urban and rural population and economic structure}

The configuration proportion of capital and labor production factors in China's urban and rural economic structure is imbalance, The amounts of labor is much larger than the amounts of capital in the agricultural industry, the amounts of capital is greater than the amounts of labor input in non-agricultural industries, This directs the result of the inefficiency of the two sectors output. The employment of labor force reached 283.18 millions in the primary industry in 1978, accounting for $70.5 \%$ of the total labor force, but the infrastructure investment in the primary industry was only 1.795 billion yuan, accounting for 3.58\% of the national total infrastructure investment; In the non-farm secondary and tertiary industries the labor force was only 118.35 millions, accounting for $29.5 \%$ of the total labor force, but the infrastructure investment were 48.304 billions yuan in the non-farm of the secondary and tertiary industries, accounting for $96.42 \%$ of the total infrastructure investment. That is, each person had an average of 6.34 yuan infrastructure investment in the agricultural industry, while each person had an average of 408.15 yuan infrastructure investment in the non-agricultural secondary and tertiary industries, it was 64.38 times of the first industrial average own the infrastructure investment, but the non-agricultural second and tertiary industries per capita GDP was only close to the 6.1 times of the agricultural industry per capita GDP.

It has some changed over time that the allocation ratio of capital and labor serious asymmetry in agriculture-related and the non-agricultural industries, because the urbanization development promote rural population decline, and the employments has also been decline in agriculture-related primary industry. However, Factor allocation imbalance has not changed much in the agriculture-related industries and the non-agricultural secondary and tertiary industries , It is mainly due to that the ratio of annual fixed assets investment of the whole society in the agriculture-related industrial is too low, the highest proportion of the total investment is less than $5 \%$ of whole society's fixed assets investments. Between the 1980 and 1994 the highest investment ratio is1980, the social investment in fixed assets investment in the agriculture-related primary industry is $4.4659 \%$ of whole society's fixed assets investments, During this period the proportion of fixed assets investment of the whole society in the agriculture-related industry also continued to decline, in 1994 it reached the lowest and it is only $0.88 \%$ of the whole society total investment. From the period 1999 to 2011, the proportion was maintained at $2.4 \%$ to $2.8 \%$, Wherein only 2002 and 2009 , it reaches the weak height at the $3 \%$ of the whole society total investment.. 
In other words, the investment proportion in agriculture-related industry is too low, a direct result is that labor and capital allocation imbalance had been exist in China's agriculture-related primary industry and the non-agricultural industries economy, The non-efficiency of the two sector's output has been maintained. The employments of labor force reached 265.94 millions in the primary industry in 2011, accounting for 34.8\% of the total labor forces, but the fixed asset investment $t$ in the primary industry was only 875.78 billions yuan, accounting for $2.811635 \%$ of the total investment in fixed assets of the whole society; In the non-farm secondary and tertiary industries the labor force are 342.27 millions, accounting for $65.2 \%$ of the total labor forces, but the fixed investment are 30.27273 trillions yuan in the non-farm of the secondary and tertiary industries, accounting for $97.18837 \%$ of total fixed asset investment of the whole society. That is, each person has an average of 3293.158 yuan infrastructure investment in the agricultural industry, while each person has an average of 88446.93 yuan infrastructure investment in the non-agricultural secondary and tertiary industries, it is 26.858 times of the first industrial average own the fixed asset investment, but the non-agricultural second and tertiary industries per capita GDP is only close to the 6.96 times of the agricultural industry per capita GDP. Specific data see Schedule 1 as shown below, the data are calculated from the China Statistical Yearbook.

Table 1 Per capita capitals of agricultural industries and non-agricultural industries

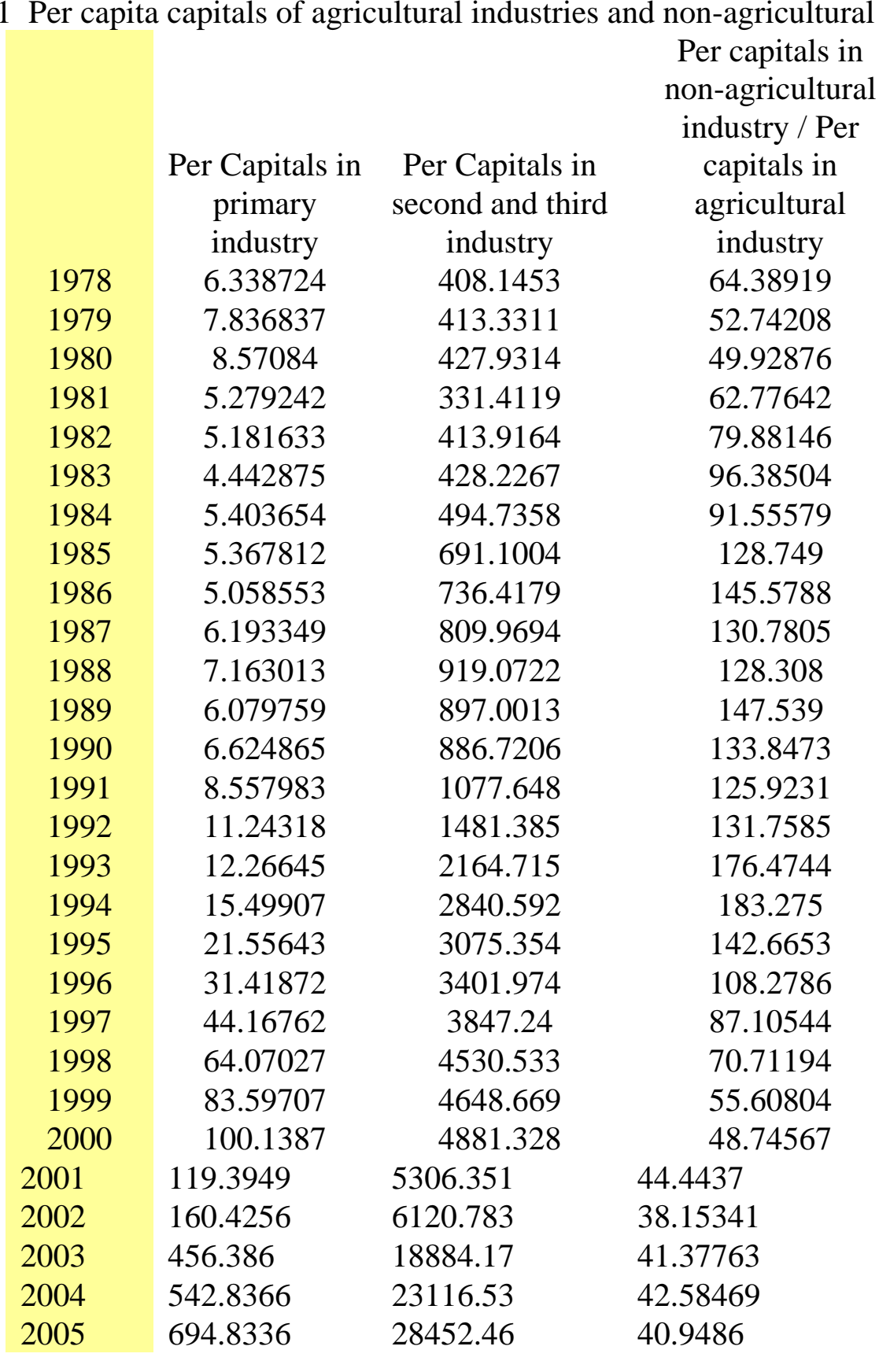




$\begin{array}{llll}2006 & 860.9429 & 34498.27 & 40.07033 \\ 2007 & 1107.515 & 42719.2 & 38.57212 \\ 2008 & 1692.495 & 52373.86 & 30.94476 \\ 2009 & 2386.591 & 66369.1 & 27.80916 \\ 2010 & 2836.665 & 81196.85 & 28.62405 \\ 2011 & 3293.158 & 88446.93 & 26.85779\end{array}$

Unit: yuan

\section{Summary}

This paper reviews the related theory to explain the present situation of China's urban and rural economic structure. Furthermore, the data of the urban and rural populations in China Statistical Yearbook is used to reveal the status of China's economic structure. It is found that the configuration proportion of capital and labor production factors in China's urban and rural economic structure is imbalance, The amounts of labor is much larger than the amounts of capital in the agricultural industry, the amounts of capital is greater than the amounts of labor input in non-agricultural industries, This directs the result of the inefficiency of the two sectors output.

\section{References}

[1] Lewis, WA Economic Development with Unlimited Supply of Labor. The Manchester School, 1954, VoL. 22, No. 2: $139 \sim 191$

[2] Ranis, G., \& Fei, JCH A Theory of Economic Development, The American Economic Review, 1961, Vol. 51, No. 4: $533 \sim 565$

[3] Jorgenson, DW The Development of a Dual Economy. Economic Journal, 1961, VoL. 71, No. 282: $309 \sim 334$

[4] Wang Haijun,Zhang Mao,The prediction of the evolution and development trend of China's dual economic structure [J]. Statistics and Decision 2010 (15) (in Chinese)

[5] Hu Angang, Ma Wei, Social and economic transformation in modern China: from the two-sector to four-sector (1949-2009) [J]. Tsinghua University (Philosophy and Social Sciences) 2012 (1) (in Chinese)

[6] Zhang Yinglu, Chen Zhigang, urban-rural dual economic structure: determination taend of changes and policy options [J]. Issues in agriculture economy (IAE) 2011 (11) (in Chinese)

[7] Li Qideng, The structure rigid reason of China's urban-rural dual economic and its softening Digestion [J]. Economic Research Guide 6, 2009 (in Chinese)

[8] Wang Sijun, Zhou Zhigang, Wu Qingfa,The analysis of urbanization effects on industrial investment under the conditions of the dual economic structure - Ningbo [J] Journal of Population Studies 1992 (01) (in Chinese)

[9] Tie Chongyuan, The analysis of origin of the Chinese dual economic structure and policy advice [J]. Occupation ring 2007 (22) (in Chinese)

[10] Liu Na, The Rethinking of the Theory about the dual economic structure [J]. The Cooperation Economy and Technology, 2010 (9) (in Chinese) 